\title{
Foucault e a
}

teoria queer: seguido de Ágape $e$ êxtase orientações pós-seculares

Mário Jorge de Paiva ${ }^{1}$

\section{Foucault and} queer theory: followed by Ágape and ecstasy - post secular orientations 


\title{
Resumo
}

O presente texto é uma resenha crítica do livro Foucault e a teoria queer: seguido de Ágape e êxtase - orientações pós-seculares, obra composta por dois textos de Tamsin Spargo e um posfácio de Richard Miskolci. Em que observaremos os acertos e os pontos falhos do livro, mostrando como seu maior mérito é realizar uma didática introdução a Teoria Queer, e sua relação com Michel Foucault, mesmo que o texto termine por não se aprofundar em uma série de questões mais avançadas.

Palavras-chave: Foucault; Teoria Queer; Pós-Secularismo.

\begin{abstract}
This text is a critical review of the book Foucault e a teoria queer: seguido de Ágape e êxtase - orientações pós-seculares, a work composed of two texts by Tamsin Spargo and a postscript by Richard Miskolci. We will observe the book's hits and misses, showing how its greatest merit is to make a good introduction to Queer Theory, and its relationship with Michel Foucault, even if the text ends up not delving into a series of more advanced questions.
\end{abstract}

Keywords: Foucault; Queer theory; Post-Secularism. 
Foucault e a teoria queer: seguido de Ágape e êxtase - orientações pós-seculares

O presente livro se divide em três partes. Os dois primeiros textos são de Tamsin Spargo, seguidos de um posfácio de Richard Miskolci.

A obra abre com Foucault $e$ a teoria queer, o qual é um interessante ensaio bibliográfico sobre a relação entre os dois elementos apresentados em seu título. Spargo (2017, p. 9) começa por falar como as universidades estão adotando muitas coisas queer ultimamente. Mas o que isto significa?

Seguindo Gayle Rubin, aponta que o sexo é sempre político (SPARGO, 2017 , p. 11). E como na língua inglesa queer pode ser substantivo, adjetivo ou verbo, contudo independente de seu uso, sempre se volta para aquilo que está em oposição ao normal e a normalização. Não sendo a teoria queer um arcabouço conceitual ou metodológico, e sim um acervo de engajamentos intelectuais, envolvendo as relações de sexo, gênero e desejo sexual. Logo o ensaio se volta a mostrar a relação do queer com Foucault, em suas aproximações e críticas (SPARGO, 2017, p. 13).

Aqui, todavia, o texto começa a desvelar problemas. Tanto a teoria foucaultiana quanto a teoria queer são muito vastas. E o ensaio se desvela como meramente introdutório ao tema, por ter escolhido um recorte muito grande de pesquisa.

Foucault é descrito tanto como um pioneiro no assunto quanto um possível estorvo. A autora trata então do primeiro volume de História da sexualidade, e como tal obra se relaciona com a revolução sexual dos anos 70 (SPARGO, 2017, p. 13-4). Mostrando a rejeição que Foucault realizou em relação a hipótese repressiva, um ponto muito claro em Foucault (2010).

Isto não quer dizer que Foucault rejeite qualquer elemento biológico, mas o que ele está a fazer é priorizar o papel das instituições e dos discursos. Foucault em vez de tentar achar uma verdade do sexo, tentou falar de sua produção (SPARGO, 2017, p. 15-6).

Spargo então se volta a uma das afirmações vistas como mais provocativas desse primeiro volume da História da sexualidade, a ideia de que a categoria de homossexualidade é recente, sendo fruto de um contexto do século XIX (SPARGO, 2017, p. 18). Também falando a autora como essa concepção de análise adotada se volta para a produção de um discurso reverso. O poder sempre termina por criar sua resistência, nunca sendo completo (SPARGO, 2017, p. 20). 
Fazendo a autora então uma correlação entre o discurso reverso e o nascimento das políticas identitárias (SPARGO, 2017, p. 21).

Na sequência, Spargo começa a explicar os volumes 2 e 3 da História da sexualidade. Abordando como foi a cultura cristã que efetivamente rompeu com todo o modelo ético do mundo clássico (SPARGO, 2017, p. 23). E esse é o problema das simplificações. Como vemos, melhor em Foucault (2019), não houve um rompimento, mas profundas continuidades entre o pensamento pagão e a moral cristã dos primeiros séculos. Cristãos famosos faziam referências, diretas ou indiretas, aos filósofos, para somá-los com o conhecimento das sagradas escrituras.

Spargo (2017, p. 23) então aborda como o principal catalisador de Foucault para a teoria queer foi o modelo de construção discursiva das sexualidades. Foucault não foi o primeiro a falar disto, mas é inegável seu maior impacto, mesmo quando muitos elementos de sua obra terminam por serem revisados e criticados.

Trata também da relação, nos anos 70, entre as teorias e os movimentos feministas e de libertação gay. Sendo mencionados, por exemplo, os casos: do Campaign for homosexual equality, na Grã-Bretanha, e o Gay activists alliance, nos Estados Unidos (SPARGO, 2017, p. 26).

E sobre os atores, prazeres e identidades que, dentro da comunidade gay, causavam dissidência? Bissexualidade, transexualidade, sadomasoquismo e identificação transgênero, como elementos que desafiavam a política assimilacionista. Também se criticando elementos identificados como privilegiadores da classe média branca ou do masculinismo (SPARGO, 2017, p. 27).

Divergências que culminaram na guerra dos sexos. Pois lésbicas sadomasoquistas, feministas anti-censura, ou pró-pornografia, etc., se juntaram para contestar a ideia de uma sororidade lésbica harmônica (SPARGO, 2017, p. 28). E com o aparecimento do HIV, tais coletivos cindidos tiveram de enfrentar a renovação da homofobia. O que levou gays e lésbicas também a um radicalismo renovado e descentralizado (SPARGO, 2017, p. 29).

Foi em tal contexto, contra o assimilacionismo e contra a homofobia renovada, que o termo queer foi empregado em sua conotação atual. O Queer 
Foucault e a teoria queer: seguido de Ágape e êxtase - orientações pós-seculares

Nation e o Pink Panthers organizaram patrulhas de rua para: conter agressões contra gays, homenagear vítimas, promover atos de conscientização e organizar campanhas midiáticas. A palavra queer estava no centro da retórica (SPARGO, 2017, p. 31).

As pessoas que achavam as identidades gays e lésbicas inadequadas, restritas, podiam se identificar mais com o queer, havendo certas sobreposições significativas (SPARGO, 2017, p. 32). O queer como o permanentemente excêntrico. Em uma soma que pode se empregar de diversos teóricos do pósestruturalismo (SPARGO, 2017, p. 33).

Para Spargo alguns estudos queer dão continuidade a busca do projeto de Foucault. Identificando como exemplos importantes: David Halperin, Gayle Rubin e Martha Vicinus. Mas como autores relacionados ao queer também cita: Cindy Patton, Simon Watney, Joseph Bristow, Ed Cohen, Jonathan Dollimore, Lee Edelman, Alan Sinfliend, Yvonne Yarboro-Bejarano, Eve Kosofsky Sedgwick, Diana Fuss, Judith Butler etc. (SPARGO, 2017, p. 35-8).

A inter-relação entre a teoria de Foucault e Judith Butler ganha mais espaço. É citado o livro Problemas de gênero, como talvez o maior marco dos anos 90 para a teoria queer. Mas Spargo (2017, p. 43-4) não abraça a teoria de Butler de modo acrítico. Falando como a teoria da performatividade se mostra confusa, e que o estilo de escrita de Butler é difícil e opaco.

Nessa busca de se pensar no não binário, Spargo vê relação com as técnicas de si, analisadas por Foucault.

O ensaio termina falando que o queer hoje é criticado por sua abstração, sua transgressão. Mas a autora fala como uma série de críticas parte de uma concepção reducionista. E esse parece ser o risco maior para Spargo, se o queer se torna normal, mais um elemento de alguma coisa, deixará de ser queer. Porém a autora ainda vê potencialidades no queer.

O segundo ensaio Ágape e êxtase - orientações pós-seculares desenvolve, a inter-relação entre sexualidade e religião. Assim é uma soma entre o queer e o pós-secularismo. Mas tal texto sofre do mesmo problema do anterior, pareceu querer abarcar um tema muito grande, deixando muitas coisas por desenvolver. 
Em nenhum momento a autora explica exatamente o que viria a ser o mundo pós-secular. Mesmo que cite o 11 de setembro como um dos eventos que fez a academia despertar um renovado interesse sobre as religiões.

O pós-secular é apresentado como um conceito desenvolvido por Jürgen Habermas, marcando um novo conjunto de prioridades na crítica cultural e social da vida contemporânea (SPARGO, 2017, p. 64).

Slavoj Žižek, Alain Badiou, Giorgio Agamben etc., são vistos como autores que buscam formas de reação contra alguns efeitos da economia hegemônica do mercado global (SPARGO, 2017, p. 68). Sendo a religião um possível elemento de crítica.

Quando a autora trata de ágape, está fazendo referência ao livro 0 absolutamente frágil de Žižek. Ágape é amor, mas Žižek usa o conceito como uma contrapartida para se desafiar a economia libidinal (SPARGO, 2017, p. 72). É a busca por um amor que fuja do capitalista global.

Já o êxtase a autora relaciona com o estar fora, das nossas normas sociais ou de si mesmo. Está relacionando o conceito com algo estranho, algo queer. Refletindo inclusive sobre como a posição dos cristãos LGBT se mostra um assunto acalorado (SPARGO, 2017, p. 74).

Spargo acredita que a teoria queer pode contribuir para se desenvolver novas orientações éticas, não assentadas em fundamentos de exclusão (SPARGO, 2017, p. 76).

Tratando de revisões provocativas da religião, como: John Schad em Queerfish, Transformance de Jeffrey Q. McCune Jr. e os estudos de Marcella Althaus-Reid, vista como uma das mais importantes teólogas queer. Spargo (2017, p. 78), seguindo Althaus-Reid, relembra como o divino se apresenta no terreno dos marginalizados (SPARGO, 2017, p. 78).

Seria interessante também a autora ressaltar como há teólogos que investem em leituras de aceitação bíblica, mas que não fazem parte da teoria queer, é o caso de James Alison (2010), acreditamos. Porém tal ponto não é abordado.

Juntando tais ideias, com os conceitos de ágape e êxtase, a autora vê potencial em ajudar a desenvolver formas de pensar sobre a fé, e de se conviver com ela, dentro do mundo pós-moderno (SPARGO, 2017, p. 79). 
Foucault e a teoria queer: seguido de Ágape e êxtase - orientações pós-seculares

O livro termina com um posfácio de Miskolci, chamado Estranhando Foucault: uma releitura queer de História da sexualidade I. Tal posfácio ajuda a inserir Foucault em seu tempo histórico, porém fala pouco da obra em questão de Spargo.

Em suma: o livro levanta muitos pontos interessantes, se utilizando de um rico aporte, porém poderia ter aprofundado mais suas discussões existentes.

Artigo recebido em 27 de julho de 2020. Aprovado para publicação em 06 de outubro de 2020.

\section{Referências}

ALISON, James. Fé além do ressentimento. São Paulo: É realizações, 2010.

FOUCAULT, Michel. História da sexualidade 1: a vontade de saber. São Paulo: Graal, 2010.

FOUCAULT, Michel. História da sexualidade IV: As confissões da carne. Lisboa: Relógio D’Água, 2019.

SPARGO, Tamsin. Foucault e a teoria queer: seguido de Ágape e êxtase orientações pós-seculares. Belo Horizonte: Autêntica, 2017. 